\title{
In Remembrance of Shoshichi Kobayashi
}

\section{by Takushiro Ochiai}

This is a translation into English of a portion of my article "Kobayashi-sensei wo shinonde," which appeared in Suugaku Seminar, 2013.

The life and academic achievements of Shoshichi Kobayashi give a vivid sample of what a great mathematician should be. He left us numerous masterpieces of high originality, comparable to great musical compositions enchanting audiences; his books, taken as a whole, harmonize splendidly into a great symphony. Though aware of my inability to reach the height of his talent, I dare to write this article to bring attention to the fine personal character and remarkable academic achievements of Shoshichi Kobayashi, outstanding mathematician, mentor and colleague.

\section{Great creation}

Kobayashi published papers in academic journals every year without fail, starting from his virgin paper in 1954 until his last days. Among a total of 134 papers, there are 85 singleauthor papers and 49 collaborative works. A unique feature of his single-author publications is their brevity; e.g., there are 34 papers of less than 5 pages, 28 papers of less than 10 pages and 15 papers of less than 28 pages. Every one of them is deep and rich in content with transparent and easily comprehensible explanations, as is evidenced by his invention of the concepts of the so-called "Kobayashi distance", hyperbolic complex manifolds and the Hermitian-Einstein vector bundles. Inspired by Chern's result, which further improved on the generalization of the classical Schwarz's lemma by L. Ahlfors ("The holomorphic maps between Hermitian manifolds" by S.S.Chern), Kobayashi became interested in Schwarz's lemma and read all the related papers, one by one. He especially admired Caratheodory's point of view to which he devoted himself and took advantage of the holomorphic maps, which he admitted led him to the discovery of the "Kobayashi distance".

We can classify his papers into the following fields:

- geometry of connection

- geometric transformation groups

- complex manifolds and holomorphic maps

- geometry of complex vector bundles

Utilizing his many works, expanding them with attention to their historic background and development, Kobayashi subsequently published thirteen self-contained books, every one of which is easily comprehensible by graduate students. Professor Kobayashi had once said to me: "When I write books, I prepare one or two years for

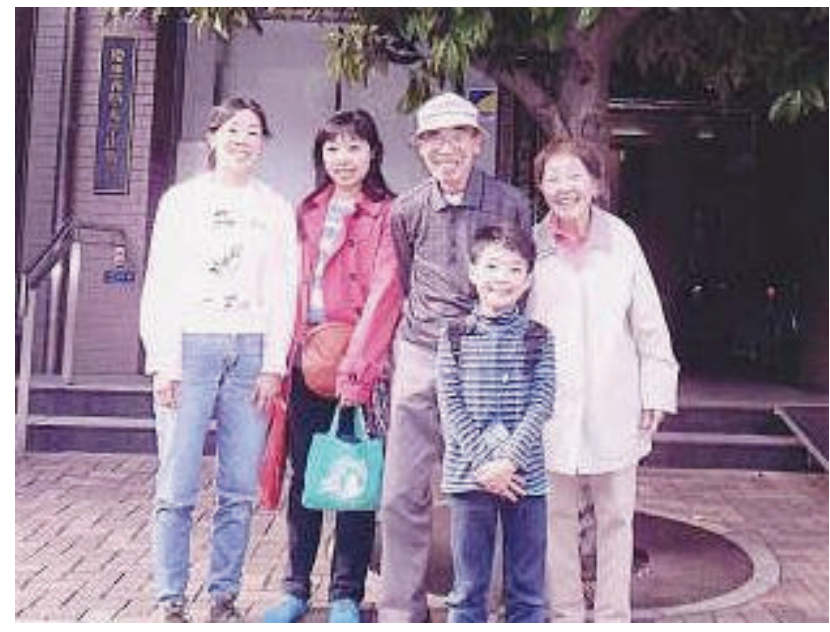

At Keio University's Mita Residence, May 2012. From left to right: Mei Kobayashi (2nd daughter), Mrs. Eriko Shinozaki (a former student at International Christian University Tokyo), Kobayashi, Mrs. Shinozaki's son, and Mrs. Kobayashi.

the first manuscript and make certain to give lectures based on it for one or two years in order to deepen the contents before finally completing the final manuscript."

\section{Transparent mathematical philosophy}

To convey to the public his philosophy of mathematics, or rather of differential geometry, I include here passages from his essays in Japanese as published in well-known magazines on mathematical sciences, and which deeply reflect his mathematical achievements. The transparency, beauty, and open mindedness of his viewpoints, which he sharpened well to the limit, are my personal and eternal desire.

Differential geometry is one viewpoint over mathematics and a method. When various fields in mathematics reach the point of being well understood, the phenomenon called "algebraization" occurs. I think, however, it is possible to see different fields of mathematics from a differential geometric viewpoint as well as from an algebraic viewpoint. The raison d'etre of differential geometry is to offer a new viewpoint and powerful methods rather than itself being considered like a theory of numbers. Moreover, the 
concepts and methods understood from a geometric point of view are so natural (different from artificially created nonsense) that development beyond anticipation later occurs in many cases. Differential geometry can produce limitless developments by carrying its methods into all the fields of mathematics. It is especially important, then, to know how to make use of the differential geometric method to make connections in fields such as the theory of functions (one or several complex variables), algebraic geometry, topology and differential equation theory. ${ }^{1}$

When a theorem in differential geometry is proved by the concepts and techniques of differential geometry, and its argument remains in the closed world of differential geometry, I cannot get so excited, even if it is a good theorem to be admired. I feel true joy when differential geometry and other fields are connected well enough for problems to be solved by the techniques of differential geometry. When I came to know Chern's work, which clarified thoroughly the essence of Nevanlinn's theorem by differential geometric methods, I wanted to borrow the word "Eureka" which Archimedes cried out when he found the method to determine the degree of pure gold in the crown while taking a bath. Anyone doing mathematics is naturally elated when he can say: "Ah, I got it!" but he is truly ecstatic when he unexpectedly finds an interaction between two fields. ${ }^{2}$

Wonderful theorems in mathematics are proven with breakthroughs of originality which cause everyone to understand them. A mathematician gets the greatest feeling of happiness when he finds such a new idea. A problem, which is solved merely by understanding and following a routine process, is a petty problem, and a theorem whose proof does not use any idea which comes involuntarily, is really tedious. It seems that any problem which does not open a new field, or any result which has no application in any other field of mathematics, disappears after a while. An eternal life is given only to a beautiful result. ${ }^{3}$

Some percentage of the work in mathematics consists of the creation of suitable notation. Suitable notation makes calculations easy to handle, makes formulas look beautiful and easy to memorize, and makes theorems apparent at a glance. Suitable notation is important not only from a passive role to make descriptions beautiful and easy, but also from an active role, even to suggesting what should be done next. We cannot explain in one word what kind of notation is suitable or what kind of theorem is good. It is a mathematical sense that will take it in somehow. ${ }^{4}$

\footnotetext{
${ }^{1}$ Suurikagaku, August, 1965

${ }^{2}$ Suugaku Seminar, April, 2003

${ }^{3}$ Suugaku Seminar, December, 1965 issue

${ }^{4}$ Suugaku Seminar, September, 1967
}

When you study subjects in mathematics which are not restricted to calculus, I would like to urge you to study the history of its development together by all means. Since modern mathematics requires too much stringency, lectures as well as textbooks rarely touch historical background. However, I think that one can understand the subject more deeply by getting to know the history and "why this concept was produced." I want people who become school teachers to study the history of mathematics by all means. ${ }^{5}$

\section{Through our 50 year relationship}

Finally, please allow me to tell you my private experience with Kobayashi through our acquaintance over 50 years. I met him in the winter semester of 1965 when I was a senior in the mathematics department at the University of Tokyo. For Kobayashi, it was supposed to be a short stay with his family in Tokyo on a round trip by a transpacific line for the first time after 12 years absence, since the time he left Japan in 1953 for France. At that time I had studied many of his papers in the mathematical journals available at the library in the mathematics department. He was the author of the famous book Foundation of differential geometry, Volume 1, which was very expensive because of the poor reserve status of foreign currency in Japan, so I imagined that he would have the same atmosphere as the old professors in the mathematics department. However, when I met a young man with a faint smile, who seemed to be one of the assistants in the mathematics department, and said, "Professor Kobayashi is coming to our department, isn't he?" he replied, "I am Kobayashi". I still remember how surprised I was at his youthfulness. To my further surprise, he also confessed to me that his first name "Shoshichi" in Chinese characters means that he was born in the seventh year of the reign of the Emperor Shouwa (namely 1932).

I first attended his series of lectures on "G-structure and pseudo group structure".

Through these lectures, I understood clearly what I had self-educated randomly in various opportunities and studies along my way. I would not be exaggerating to say that it was the most comprehensible lecture I ever heard in my entire life.

Although I was assigned to prepare lecture notes of his lectures, since it was the first time in my life to do so without understanding exactly how to do it, I wrote the notes by supplementing in my own way, the explanations, proofs and examples he omitted during the lectures, which were then published as the mathematics department monograph. Much later, Mrs. Kobayashi told me that he had said to her with a smile "Ochiai wrote lecture notes which are more superb than my original lecture ". Whenever I recall this episode, I cannot but feel the deep generosity of his mind.

${ }^{5}$ Suurikagaku, February, 2001 
Due to this experience, I completed my master thesis proving that the transformation group leaving a geometric structure of elliptic type is a finite dimensional Lie group, and which was published in the journal of the mathematics department.

After the completion of the master program, by support from the Fulbright Fellowship, I enrolled in the graduate school of Notre Dame University from 1967 till 1969 with Professor Tadasi Nagano as a thesis advisor. I obtained my Ph.D degree thesis on the theory of Cartan connections modeled after the symmetric R-spaces based on the G-structures of 2nd order. After the completion of doctoral program, since U.S law allowed me to stay in the U.S.A for two more years as a practical trainee, I applied for a position of lecturer in the mathematics department of UCB with the recommendation by Kobayashi and was fortunately employed. The happiest feeling was that I could spend every second of my time totally as I pleased except for preparation and deliberation of my assigned lectures. Almost everyday I dropped by his office, the door of which was always wide open, and we had lunch in the cafeteria on campus and after a nice walk, I followed him to the drugstore at the corner of Telegraph Avenue to buy the New York Times "one day late". During the time with him, every topic that came up had something to do with mathematics. That time was the most precious to me, so I studied a lot and he endured my many questions as we spent time so precious to me, talking and thinking together.

I have taken for my motto his conviction "Never deny the other's mathematical argument at first glance and always think positively and optimistically." Even if my questions and arguments had some ambiguity, he never said "That is a mistake or impossible". He never hesitated to lead our argument to a correct step and to new ideas. When nothing came out after few days of painstaking collaborative joint work, he consoled me and himself with a smile, saying "We have studied a lot, and this experience will help us definitely at some future time." I have been extremely grateful that I was able to collaborate in mathematical investigation in this way with Kobayashi.

Furthermore, I was privileged to enjoy the hospitality of his family on the several occasions, such as being served turkey carved by him when invited to the thanksgiving dinner and also to share barbecue lunch with them in Tilden Park. While at Berkeley, I stayed at the International House, where I met a girl staying also there as a student in the graduate school of architecture. We got married in his home guided by a priest. We have now two sons and two grandchildren. We are completely aware of the hearty thanks we owe him and his family for their support.

Through my acquaintance with Professor Kobayashi for many years, I am convinced that his passion for mathematics was motivated by his love for human beings and for scholarship. I am extremely fortunate to have collaborated with Professor Kobayashi on some of his mathematical work. 